\title{
Primary choriocarcinoma of the colon: a case report and review of the literature
}

\author{
Lun Jiang, Jing-Tao Wu* and Xin Peng
}

\begin{abstract}
Choriocarcinoma usually arises in the uterus and gonads. Primary choriocarcinoma (PCC) in an extragenital organ is rare. When it occurs in the gastrointestinal tract, the stomach is the most common site. Only 12 cases of PCC of the colon have been reported in the world literature. Most cases were associated with adenocarcinoma. We report the case of a 36-year-old man with PCC of the colon and review the clinical characteristics of previously documented cases.
\end{abstract}

Keywords: Adenocarcinoma, Chemotherapy, Choriocarcinoma, Colon, Syncytiotrophoblastic differentiation

\section{Background}

Choriocarcinoma is a highly malignant tumor of trophoblastic cells that most often arises in the female genital tract. It is considered to be pertinent to molar pregnancy, normal or ectopic pregnancy and abortion. When it occurs in male patients, the testis is the most common site. Choriocarcinoma of extragenital origin is found in the retroperitoneum or the mediastinum, or intracalvarium. Primary choriocarcinoma (PCC) originating in the colon is extremely rare and the prognosis is usually poor.

\section{Case presentation}

A 36-year-old male patient visited the local hospital for the chief complaint of discomfort of the upper abdomen. An appendectomy was performed under the clinical diagnosis of acute appendicitis. During the operation, a tumor was observed in the colon. The operation was aborted because of an inability to remove the tumor. Two days later, a computed tomographic (CT) scan of the abdomen revealed the mass arising from the ascending colon. The regional enlarged lymph nodes and metastases in the liver were noted (Figure 1).

The patient was transferred to our hospital for treatment. Tumor markers, including carcinoembryonic antigen, cancer antigen 19-9 (CA 19-9) and CA 125, were

\footnotetext{
* Correspondence: wujingtaodoctor@126.com

Department of Medical Imaging, Su Bei People's Hospital of JiangSu

Province, Medical School of Yangzhou University, No. 98 NanTong West

Road, Yangzhou, Jiangsu Province 225001, China
}

in the normal range. His serum beta human chorionic growth hormone $(\beta-\mathrm{HCG}$ ) level was $3.38 \mathrm{mIU} / \mathrm{ml}$. A colonoscopy revealed a yellow tumor in the colon (Figure 2 ) and endoscopic biopsy findings suggested a poorly differentiated adenocarcinoma. After two days, a colectomy was performed. The tumor located in the ascending colon measured $4 \mathrm{~cm} \times 5 \mathrm{~cm}$ and penetrated the serosa and the mesocolic fat, with 12 adjacent enlarged lymph nodes. The pathologic findings showed that the tumor invaded the serosa of the intestinal wall and was composed of syncytiotrophoblastic cells, cytotrophoblast-like cells and intermediate trophoblastic cells. Necrosis and hemorrhage were also noted in the mass. Immunohistochemical staining was positive for HCG and negative for cytokeratin 7 , cytokeratin 20 , villin, caudal type homeobox 2, $\alpha$-fetoprotein and CD30 (Figure 3). Metastasis was found in the liver and in eight of the excised lymph nodes.

Systemic chemotherapy using bleomycin, etoposide and platinum was performed. Chemotherapy engaging etoposide phosphate $100 \mathrm{mg}$, cisplatin $30 \mathrm{mg}$, bleomycin $18 \mathrm{mg}$ was initiated. The $\beta$-hCG level increased from 3.38 to $10,000 \mathrm{mIU} / \mathrm{ml}$ after the first course of chemotherapy, and CT showed another mass in the liver. After three cycles of chemotherapy, his $\beta$-hCG level remained high. Because of the progression of disease, the patient and his family abandoned other alternative regimens of chemotherapy.

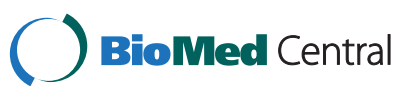

(c) 2013 Jiang et al.; licensee BioMed Central Ltd. This is an Open Access article distributed under the terms of the Creative Commons Attribution License (http://creativecommons.org/licenses/by/2.0), which permits unrestricted use, distribution, and reproduction in any medium, provided the original work is properly cited. 

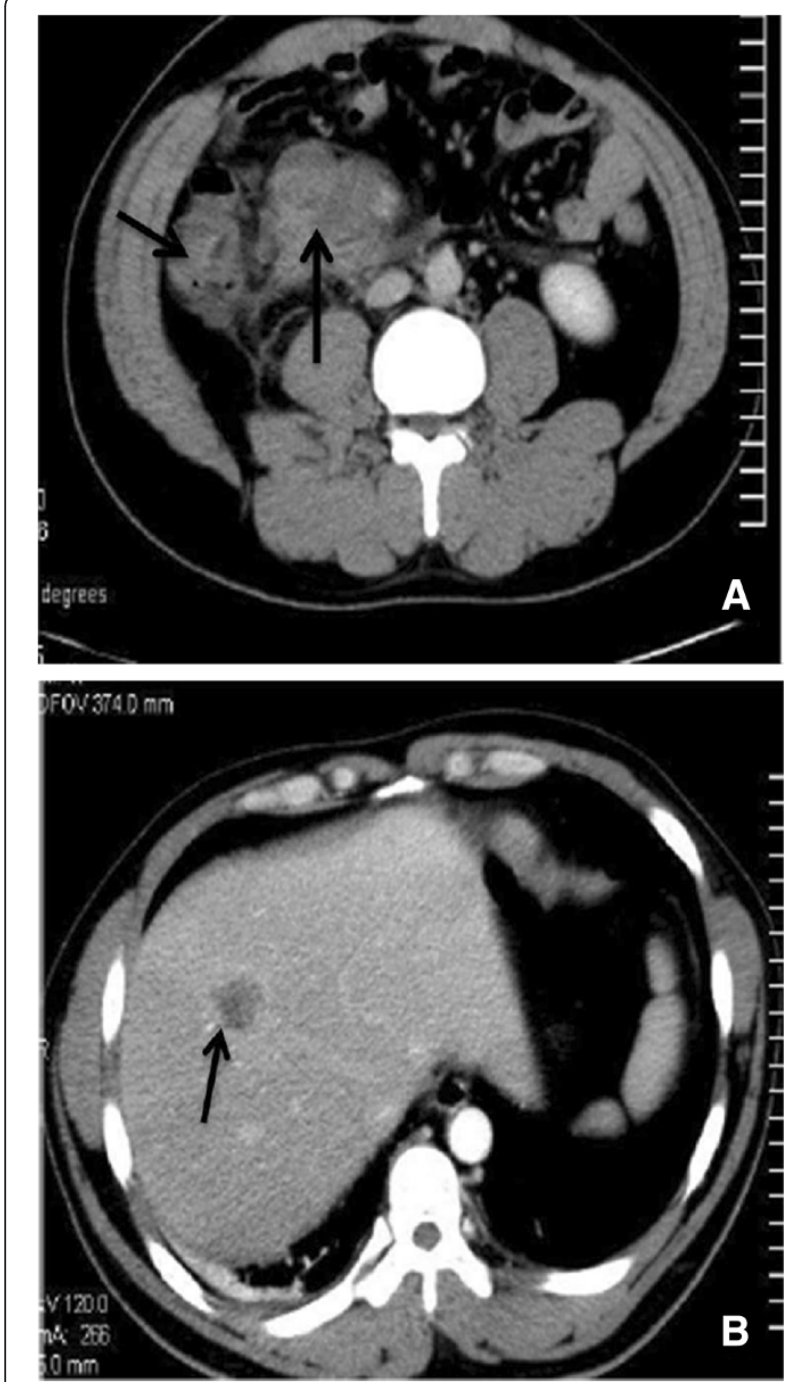

Figure 1 Computed tomography. (A) Note the thickened wall of the ascending colon (short arrow) and enlarged lymph nodes in the mesentery (long arrow). (B) The hepatic lesion manifested ring-shaped enhancement (arrow).

\section{Discussion}

Choriocarcinoma most commonly arises in trophoblastic tissue following gestational events such as molar pregnancy, normal or ectopic pregnancy, and abortion. When the tumor occurs in men, the gonads are the most common sites. Choriocarcinoma of extragenital origin has been reported in the retroperitoneum [1], mediastinum [2], and intracalvarium (especially in the pineal gland [3]). When it occurs in the gastrointestinal tract, the stomach is the most common site [4]. PCC originating in the colon is extremely rare, with only 12 documented cases. In the literature, the mean age of presentation with PCC of the colon is 51.4 years, and the ratio of female to male is 1.6:1. Of the cases reported, $61.5 \%$ of patients presented with the tumor in the proctosigmoid; the tumor was located in the ascending colon in three patients (Table 1).

The pathogenesis of primary extragenital choriocarcinoma is controversial. Several hypotheses have been proposed, including that it develops from retained primordial germ cells that migrated abnormally during embryonic development [16]; metastasis from a latent primary lesion in the genitalia [4]; and the retrodifferentiation of pre-existing colonic carcinoma [8]. Among them, the retrodifferentiation theory from pre-existing colonic adenocarcinoma is well accepted. Given that PCC of the colon associated with adenocarcinoma accounts for $69.2 \%$ of reported cases, this theory is considered to be logical. However, concurrent
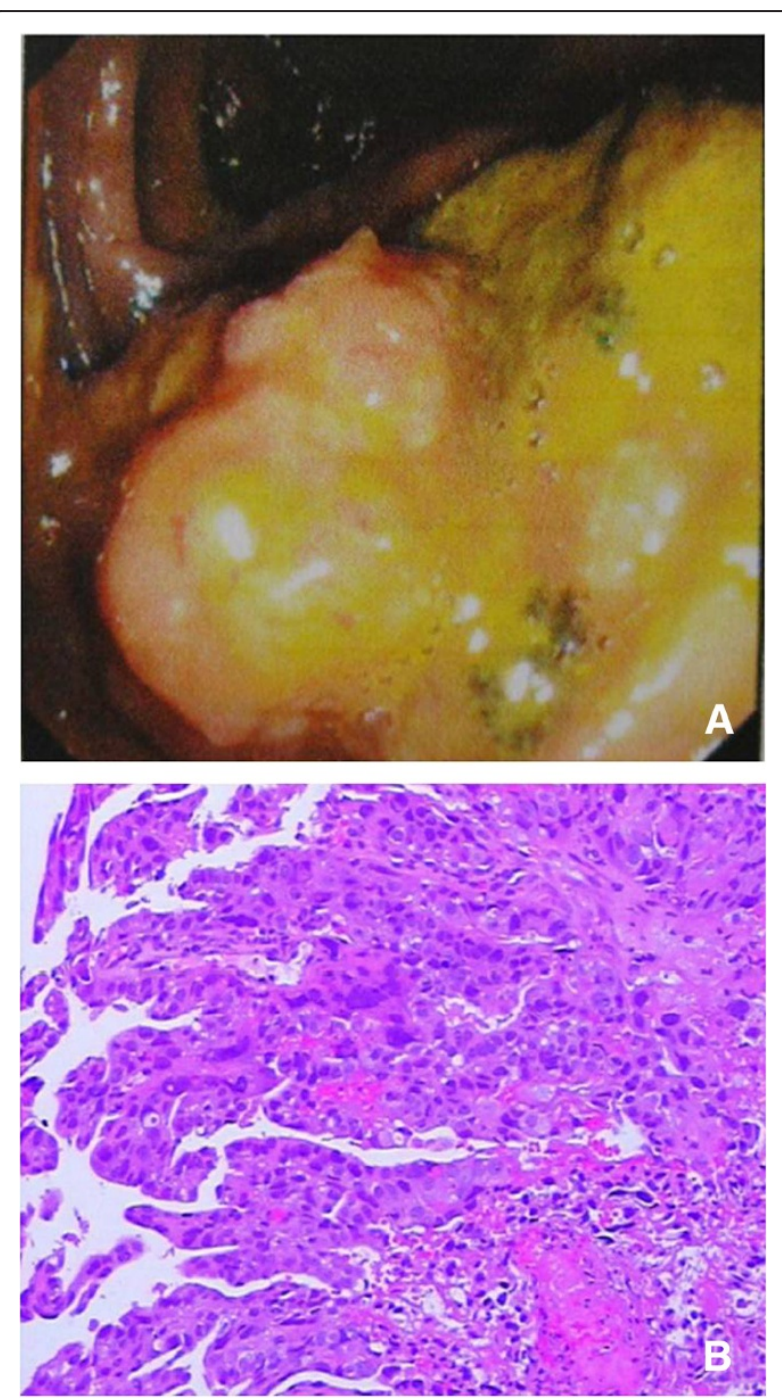

Figure 2 Endoscopic biopsy (A) Colonoscopy revealed a circular yellow tumor in the ascending colon. (B) An endoscopic biopsy revealed atypical epithelium (hematoxylin and eosin $\times 100$ ). 


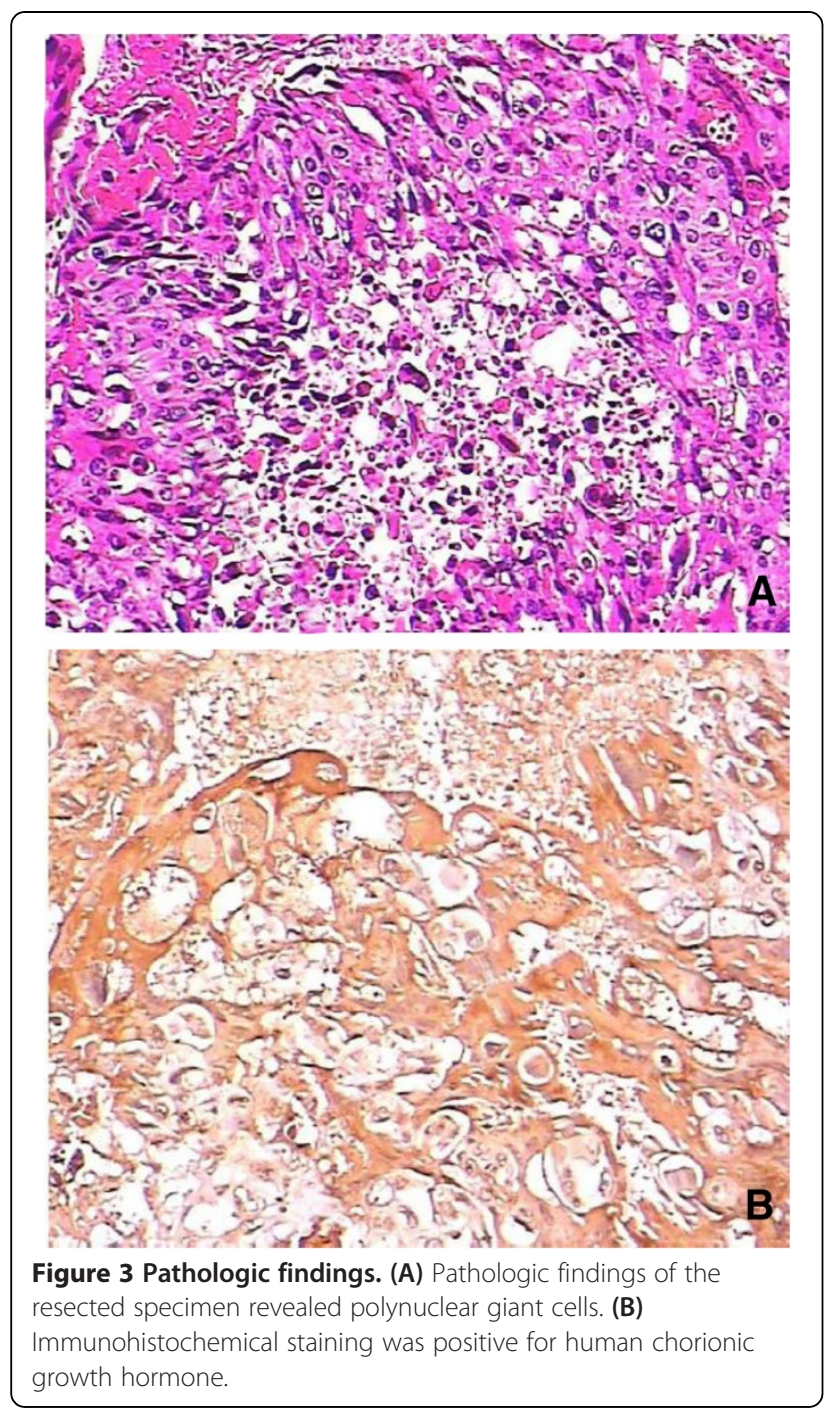

adenocarcinoma was not present in our patient nor in two of the previous cases $[10,13]$. An explanation for choriocarcinoma unaccompanied by adenocarcinoma could be that the tumor arises directly from malignant change in the ectopic chorion or totipotent cells [13].

The preoperative diagnosis of PCC of the colon is poor. In our case, the patient was assessed as having metastatic colonic cancer. An endoscopic biopsy supported this possibility because of an insufficient specimen. However, on postoperative biopsy, he was re-diagnosed with PCC of the colon. The diagnosis of primary extragenital choriocarcinoma should firstly rule out any abnormal findings in the uterus or genitalia. The presence of cytotrophoblast and syncytiotrophoblast on biopsy, the presence of $\beta$-hCG immunoreactive cells, and elevation of serum $\beta$-hCG level confirm the diagnosis.

The majority of patients with gastric choriocarcinoma are treated surgically. Umemori et al. found that resection followed by adjuvant chemotherapy was the best treatment of PCC of the lung [16]. For patients with widespread metastasis, resection has proven ineffective in prolonging survival. In patients without metastasis, a combination of radical surgery and appropriate adjuvant chemotherapy contributed to their long-term survival [4]. The chemotherapy modality for primary extragenital choriocarcinoma has not been established; most treatment options are based on experience. The chemotherapy regimens for choriocarcinoma and adenocarcinoma are different. Chemotherapy for both the choriocarcinoma and the colonic adenocarcinoma is most logical according to a study by Kubosawa et al. [4] - their patient showed the longest survival.

The correlation between the $\beta$-hCG level and the effectiveness of treatment has not been detailed in most previous reported cases. $\beta$-hCG did not decrease to normal levels after surgery, implying that micrometastatic disease existed [17]. The reduction of $\beta$-hCG in the serum indicates response to treatment. After the resection of the primary lesion, the serum $\beta$-hCG level in our case did not decrease to normal range. Abdominal CT showed hepatic lesions when the serum $\beta$-hCG increased. We suggest the serum $\beta$-hCG level could be used as a marker when assessing the effectiveness of treatment.

\section{Conclusions}

The prognosis of PCC of the colon is poor. In our analysis of the literature, the median survival time was less than 1 year. PCC of the colon is usually not identified until the tumor has generalized metastasis. The great majority of patients die from liver failure.

\section{Consent}

Written informed consent was obtained from the patient for publication of this manuscript.

\section{Abbreviations \\ $\beta$-HCG: beta human chorionic growth hormone; CA: cancer antigen; CT: computed tomography; PCC: primary choriocarcinoma.}

\section{Competing interests}

The authors declare that they have no competing interests.

\section{Authors' contributions}

Jing-Tao Wu and Lun Jiang proposed the study. Jing-Tao Wu, Lun Jiang and Xin Peng - wrote the manuscript. Lun Jiang and Xin Peng contributed equally to this work. All authors read and approved the final manuscript.

\section{Acknowledgements}

We thank Jun Sun for providing the original CT images.

Received: 8 August 2012 Accepted: 24 December 2012

Published: 28 January 2013 
Table 1 Clinical characteristics of primary choriocarcinoma of colon

\begin{tabular}{|c|c|c|c|c|c|c|c|}
\hline Case & Sex and age (years) & Location & $\begin{array}{c}\text { HCG } \\
(\mathrm{mlU} / \mathrm{ml})\end{array}$ & Metastases on admission & $\begin{array}{l}\text { Associated with } \\
\text { adenocarcinoma? }\end{array}$ & Treatment & Survival time \\
\hline Park and Reid 1980 [5] & $F / 49$ & S & NS & Liver lung & Y & Surgery & 1 month \\
\hline Nguyen 1982 [6] & $\mathrm{M} / 74$ & S & 400 & None & Y & Surgery & 10 weeks \\
\hline Ordonez and Luna 1984 [7] & $F / 35$ & Cecum & 1,612 & Regional lymph nodes, liver & Y & Surgery & 2 months \\
\hline Kubosawa et al. 1984 [8] & $\mathrm{F} / 50$ & S & 230,000 & None & Y & Surgery & 4 months \\
\hline Metz et al. 1985 [9] & $F / 42$ & S & 154,000 & Regional lymph nodes, liver, lung spleen & Y & None & \\
\hline Lind and Haghighi 1986 [10] & $M / 42$ & A & 610,000 & Liver & $\mathrm{N}$ & Surgery & 1 month \\
\hline Tokisue et al. 1996 [11] & $F / 29$ & $\mathrm{R}$ & 49,000 & Lung & Y & Surgery, chemotherapy & 11 months \\
\hline Kiran et al. 2001 [12] & $M / 68$ & R & 700,000 & Regional lymph nodes, liver & Y & None & \\
\hline Le et al. 2003 [13] & $M / 73$ & A & 146,000 & Liver, lung, brain & $\mathrm{N}$ & None & 10 days \\
\hline Verbeek et al. 2004 [14] & $F / 54$ & $\mathrm{R}$ & $6,831(P)$ & Liver, lung & Y & Surgery, chemotherapy & 8 months \\
\hline Froylich et al. 2010 [15] & $F / 57$ & Descending colon & $13,000(P)$ & Lung & $\mathrm{N}$ & Surgery, chemotherapy & 16 months \\
\hline Harada et al. 2012 [4] & $F / 58$ & S & 2,420 & None & Y & Surgery, chemotherapy & More than 60 months \\
\hline Present case 2012 & $M / 38$ & A & 3.38 & Regional lymph nodes, liver & $\mathrm{N}$ & Surgery, chemotherapy & More than 6 months \\
\hline
\end{tabular}




\section{References}

1. Okubo Y, Fukui I, Sakano Y, Yoshimura K, Maeda H, Yonese J, Yamauchi T, Kawai T, Okumura S, Ishikawa Y: Primary retroperitoneal pure choriocarcinoma. Nihon Hinyokika Gakkai Zasshi 1995, 86:1784-1788.

2. Herai Y, Nishi K, Yamamoto H, Mizuguchi M, Kasahara K, Fujimura M: A case of primary choriocarcinoma of the mediastinum in a Japanese woman. Nihon Kokyuki Gakkai Zasshi 2006, 44:384-388.

3. Chan HS, Humphreys RP, Hendrick EB, Chuang SH, Fitz CR, Becker LE: Primary intracranial choriocarcinoma: a report of two cases and a review of the literature. Neurosurgery 1984, 15:540-545.

4. Harada M, Inoue T, Hamano K: Choriocarcinoma of the sigmoid colon: report of a case. Surg Today 2012, 42:93-96.

5. Park CH, Reid JD: Adenocarcinoma of the colon with choriocarcinoma in its metastases. Cancer 1980, 46:570-575.

6. Nguyen GK: Adenocarcinoma of the sigmoid colon with focal choriocarcinoma metaplasia: a case report. Dis Colon Rectum 1982, 25:230-234

7. Ordonez NG, Luna MA: Choriocarcinoma of the colon. Am J Gastroenterol 1984, 79:39-42.

8. Kubosawa H, Nagao $K$, Kondo $Y$, Ishige $H$, Inaba N: Coexistence of adenocarcinoma and choriocarcinoma in the sigmoid colon. Cancer 1984, 54:866-868.

9. Metz KA, Richter HJ, Leder LO: Adenocarcinoma of the colon with syncytiotrophoblastic differentiation: differential diagnosis and implications. Path Res Pract 1985, 179:419-424

10. Lind HM, Haghighi P: Single case reports carcinoembryonic antigen staining in choriocarcinoma. Am J Clin Pathol 1986, 86:538-540.

11. Tokisue M, Yasutake K, Oya M, Nishisaki H, Hasegawa H, Sakoda Y, Kizaki T, Sashikata T, Morita R: Coexistence of choriocarcinoma and adenocarcinoma in the rectum: molecular aspects. J Gastroenterol 1996, 31:431-436.

12. Kiran RP, Visvanathan R, Simpson CG: Choriocarcinomatous metaplasia of a metachronous adenocarcinoma of the colon. Eur I Surg Oncol 2001, 27:436-437

13. Le DT, Austin RC, Payne SNP, Dworkin MJ, Chappell ME: Choriocarcinoma of the colon: report of a case and review of the literature. Dis Colon Rectum 2003, 46:264-266.

14. Verbeek W, Schulten HJ, Sperling M, Tiesmeier J, Stoop H, Dinjens W, Looijenga L, Wörmann B, Füzesi L, Donhuijsen K: Rectal adenocarcinoma with choriocarcinomatous differentiation: clinical and genetic aspects. Hum Pathol 2004, 35:1427-1430.

15. Froylich D, Shiloni E, Lavie O, Neumann A, Vlodavsky E, Hazzan D: Colon and lung choriocarcinoma. Isr Med Assoc J 2010, 12:642-644.

16. Umemori Y, Hiraki A, Aoe K, Murakami T, Maeda T, Matsuda E, Takeyama H Primary choriocarcinoma of the lung. Anticancer Res 2004, 24:1905-1910.

17. Froylich D, Shiloni E, Lavie O, Neumann A, Vlodavsky E, Hazzan D: Colon and lung choriocarcinoma. IMAJ 2010, 12:642-644.

doi:10.1186/1477-7819-11-23

Cite this article as: Jiang et al: Primary choriocarcinoma of the colon: a case report and review of the literature. World Journal of Surgical Oncology 2013 11:23.

\section{Submit your next manuscript to BioMed Central and take full advantage of:}

- Convenient online submission

- Thorough peer review

- No space constraints or color figure charges

- Immediate publication on acceptance

- Inclusion in PubMed, CAS, Scopus and Google Scholar

- Research which is freely available for redistribution 